\title{
Arabinofuranosylcytosine Triphosphate
}

National Cancer Institute

\section{Source}

National Cancer Institute. Arabinofuranosylcytosine Triphosphate. NCI Thesaurus. Code C105950.

A triphosphate nucleotide analog that is the metabolized, biologically active form of cytarabine. This metabolite is a competitive inhibitor of DNA synthesis. 